\title{
HCV genotype determination in monoinfected and HIV co-infected patients in Cuba
}

\author{
Licel de los Angeles Rodríguez Lay ${ }^{\mathrm{a}, *}$, Maria Caridad Montalvo Villalba ${ }^{\mathrm{a}}$, \\ Marité Bello Corredor ${ }^{\mathrm{a}}$, Susel Sariego Frómeta ${ }^{\mathrm{a}}$, Jeny Marante Hernández ${ }^{\mathrm{b}}$, \\ Santiago Dueñas Carrera ${ }^{\mathrm{b}}$, Meilin Sánchez Wong ${ }^{\mathrm{a}}$, Marcia Samada ${ }^{\mathrm{c}}$, Milay Bello Núñez ${ }^{\mathrm{d}}$, \\ Lidunka Valdes Alonso $^{a}$, Hermes Pedreira da Silva Filho ${ }^{\mathrm{e}}$, Judith M. Hübschen ${ }^{\mathrm{f}}$, \\ Mitermayer G. Reis ${ }^{\mathrm{e}}$ \\ a Institute for Tropical Medicine "Pedro Kourí, Department of Virology, National Reference Laboratory on Viral Hepatitis, P O Box 601, Marianao 13, \\ Havana City, Cuba \\ b Center for Genetic Engineering and Biotechnology (CIGB), Havana, Cuba \\ c Centro de Investigaciones Médico-Quirúrgicas, CIMEQ Havana, Cuba \\ d Ivan Portuondo General Hospital, San Antonio de los Baños, Havana, Cuba \\ e Laboratory of Pathology and Molecular Biology at Gonçalo Muniz Research Center (LPBM/CPqGM), FIOCRUZ Bahia-Brazil \\ f Institute of Immunology, CRP-Santé/Laboratoire National de Santé, Luxembourg, Luxembourg
}

\section{A R T I C L E I N F O}

\section{Article history:}

Received 23 January 2012

Received in revised form 6 August 2012

Accepted 6 August 2012

Available online 15 October 2012

\section{Keywords:}

$\mathrm{HCV}$

HIV

HCV/HIV co-infection

Molecular epidemiology

Phylogenetic analysis

Risk groups

\begin{abstract}
A B S T R A C T
With the aim to characterize the HCV genotype distribution in Cuba, sera were collected from two subgroups: HCV-monoinfected and HCV/HIV co-infected patients. A combination of reverse transcription-PCR using genotype-specific primers, restriction fragment length polymorphism and sequencing was used to determine the genotype of 84 samples. Seventy-nine (94\%) showed single infections (10 [12\%] were genotype 1a and 69 [82\%] genotype 1b) and 5 (6\%) samples corresponded to mixed infections (2 [2\%] with genotypes $1 \mathrm{a} / 3 \mathrm{a}$ and 1 sample [1\%] each with $1 \mathrm{~b} / 3 \mathrm{a}, 1 \mathrm{~b} / 4 \mathrm{a}$ and $1 \mathrm{a} / 1 \mathrm{~b} / 3 \mathrm{a})$. HCV/HIV co-infected subjects had a higher frequency of mixed infections $(\mathrm{p}=0.08)$, infection with genotype $3 a$ $(p=0.18$ ) and for the first time genotype $4 a$ was found. There was no association of any demographic characteristics with any specific genotype although HCV/HIV co-infected patients showed a tendency to have mixed genotypes in those older than 45 years of age $(\mathrm{p}=0.11)$. Phylogenetic analysis showed that HCV isolates clustered with subtypes $1 \mathrm{~b}$ ( $\mathrm{n}=15$, maximal genetic distance $2.51 \%$ ) and $1 \mathrm{a}(\mathrm{n}=2$, maximal genetic distance $0.35 \%)$. This report presents the prevalence of HCV genotypes in monoinfected and HIV co-infected patients, mixed HCV infections in HCV/HIV co-infected men who have sex with men with high-risk sexual practices and for the first time identifies that the uncommon genotype $4 \mathrm{a}$ can be present in a patient co-infected with HIV.
\end{abstract}

(C) 2012 Royal Society of Tropical Medicine and Hygiene. Published by Elsevier Ltd. All rights reserved.

\footnotetext{
* Corresponding author. Tel.: +537 2553546; fax: +537 2046051.

E-mail address: licel@ipk.sld.cu (L. de.los Angeles Rodríguez Lay).
}

\section{Introduction}

Hepatitis $\mathrm{C}$ virus (HCV) infection is a major global cause of chronic liver disease. The estimated number of $\mathrm{HCV}$ infected subjects worldwide is increasing, and now numbers approximately 170 million people. ${ }^{1}$ In Cuba, 
the seroprevalence of HCV infection is low in the general population ( 0.6 to $1.9 \%)^{2,3}$ and in blood donors (0.7 to $0.8 \%)^{3,4}$ However, it is higher in risk groups such as people with hemophilia, plasmapheresis blood donors, patients with onco-hematological diseases and multitransfused hemodialysis patients (59, 47.3, 19.5 and $95.6 \%$ respectively). ${ }^{3,4}$ The Cuban HIV/AIDS epidemic has the lowest prevalence rate of the Caribbean region, and by the end of 2011, the island had 15824 patients living with HIV1 (National Registry of HIV/AIDS, Cuba). Studies in Cuba showed that in HIV-positive patients, $14.2 \%$ were positive for anti-HCV antibodies, and of them $77.7 \%$ were also positive for HCV-RNA. ${ }^{5}$ Risk factors for parenteral exposure to both viruses clearly influence the risk of co-infection. In addition, the accumulated evidence suggests that HCV behaves like an opportunistic infection in people with HIV infection. ${ }^{6}$

The distribution of different HCV genotypes and subtypes varies geographically. Genotypes 1, 2 and 3 are prevalent in Europe, Japan, United States and Latin America; genotype 4 in Central and North Africa and in the Middle East; genotype 5 in South Africa and genotype 6 in Hong Kong and Viet Nam. Each of the six main genotypes is equally divergent from the others, differing at $31-34 \%$ of nucleotide positions on pairwise comparison of complete genome sequences and the variation among different subtypes is $15-30 \%$. These differences result in approximately $30 \%$ amino acid sequence divergence in the encoded polyproteins. Patients chronically infected with $\mathrm{HCV}$ require significantly different durations of therapy and achieve substantially different sustained virologic response rates to therapies, depending on the HCV genotype with which they are infected. ${ }^{7,8}$ This fact together with the possibility that different genotypes could affect diagnostics assays and the natural history of the disease has motivated a series of molecular epidemiology studies. However, prevalence rates of genotypes appear to be changing different populations with the emergence of different genotypes in diverse parts of the world, causing differences in the survival rate of the patients. ${ }^{7-9}$

Sequence variation is equally distributed throughout the HCV viral genome, apart from the highly conserved $5^{\prime}$ non-coding region ( $5^{\prime} \mathrm{NCR}$ ) and core, and highly variable HVR1 (hypervariable region 1) in E2. Because of its sequence conservation, the $5^{\prime} \mathrm{NCR}$ is the target of most $\mathrm{HCV}$ detection and quantification assays. This $5^{\prime} \mathrm{NCR}$ also contains genotypically variable sequence positions which permit discrimination of all of the major genotypes and many of the subtypes of HCV. Procedures based on $5^{\prime} \mathrm{NCR}$ can be considered the most adequate for genotyping in clinical practice. The core region, although less conserved than the $5^{\prime} \mathrm{NCR}$, is the most conserved region in the HCV genome open-reading frame and the most conserved protein in different genotypes. ${ }^{10-12}$

Little information regarding $\mathrm{HCV}$ genotype circulation and phylogenetic analysis of HCV strains is available from Cuba. ${ }^{13-15}$ None of the studies have analyzed HCV infection within different populations and risk groups. Because each group has its own clinical and epidemiological characteristics, it is vital to know the distribution of HCV genotypes for the follow-up of chronic infections.

\section{Materials and methods}

\subsection{Study population}

Serum samples from 109 patients who were confirmed as anti-HCV positive by a third generation immunoassay were included. The samples were received in the National Reference Laboratory on Viral Hepatitis for HCV molecular diagnosis and were stored at $-20^{\circ} \mathrm{C}$ until use. For analysis purposes the population was divided into two main subgroups: HCV-monoinfected $(\mathrm{n}=63)$ and $\mathrm{HCV} / \mathrm{HIV}$ coinfected $(\mathrm{n}=46)$ patients. The samples were collected from 2001 to 2005 in the first subgroup, and from 2007 to 2008 in the second. The demographics, epidemiological and clinical characteristics of the study population are summarized in Table 1. Patient data were collected from medical charts.

\subsection{Laboratory assays}

\subsubsection{RNA extraction, reverse transcription, $P C R$ reaction and genotyping by RFLP analysis ( $n=63$ )}

Total RNA was extracted from $200 \mu \mathrm{L}$ of serum with Trizol LS (Invitrogen Life Technologies, Carlsbad, CA, USA), followed by chloroform extraction and isopropanol precipitation. The RNA pellet was washed with $70 \%$ ethanol ( $\mathrm{vol} / \mathrm{vol})$ and then briefly air dried and redissolved in $20 \mu \mathrm{L}$ of RNAse/DNAse free water. The RNA was reversetranscribed into cDNA using MMLV $(200 \mathrm{U} / \mu \mathrm{L})$ and random hexamer primers $(50 \mu \mathrm{M})$ during 90 minutes at $37^{\circ} \mathrm{C}$. Following transcription, the cDNAs were amplified by nestedPCR targeting the 5' NCR using primers 209, 939, 211 and $940 .{ }^{16}$ Genotype and subtype determination of $\mathrm{HCV}$ strains was done by cleavage of the amplified $5^{\prime}$ NCR using restriction enzymes (HAE III, RSA I, MVA I, HINF I, BSTU I and $S C R F I$ ) that recognize sequence polymorphisms between six HCV genotypes: 1( $a$ and $b$ ), 2 ( $a$ and $b$ ), 3 ( $a$ and $b$ ), 4,5 and $6 .{ }^{17}$

\subsection{2. $P C R$ reaction and genotyping using specific primers targeting the core region ( $n=109)$}

After RNA extraction and CDNA synthesis, a nested PCR was performed using in the first PCR reaction primers 256 and 186 NTER and in the second reaction a mix of 10 (four sense and six antisense) primers specific for the amplification of four different HCV genotypes: 1 (a and b), 2, 3 (a) and 4. This primer combination produces PCR products of the following sizes: $125 \mathrm{bp}$ for genotype 1a; $141 \mathrm{bp}$ for $1 \mathrm{~b} ; 75 \mathrm{bp}$ for 2; $87 \mathrm{bp}$ for $3 \mathrm{a}$ and $336 \mathrm{bp}$ for 4 a. $^{11}$

\subsubsection{Amplification of the 5' NCR and part of the core gene, $P C R$ product purification, sequencing and phylogenetic analysis $(n=48)$}

In addition, the cDNAs were amplified by nested-PCR directed to the $5^{\prime}$ NCR and part of the core gene of the HCV genome (spanning nucleotide positions of $107-452$ ). ${ }^{18}$ The amplified PCR fragments were purified using the QiaQuick PCR purification Kit (Qiagen, Valencia, CA, USA) and sequenced in both directions using the dideoxynucleotide terminator method, with the ABI Prism 3100 Genetic 
Table 1

Characteristics of the 109 patients enrolled in the study, Cuba

\begin{tabular}{|c|c|c|}
\hline Parameters & HCV-monoinfection, $\mathrm{n}=63$ (58\%) & HCV/HIV co-infection, n=46 (42\%) \\
\hline \multicolumn{3}{|l|}{ Gender } \\
\hline Male & $36(57 \%)$ & $37(80 \%)$ \\
\hline Female & $27(43 \%)$ & $9(20 \%)$ \\
\hline \multicolumn{3}{|l|}{ Age, years } \\
\hline Children & 9-18 (median 14.2), 5 (7.9\%) & 0 \\
\hline Adults & 26-70 (median 41.2), 58 (92.1\%) & 24-50 (median 35.2), 46 (100\%) \\
\hline \multicolumn{3}{|l|}{ Skin color } \\
\hline White & $39(62 \%)$ & $36(78 \%)$ \\
\hline Non-white & $24(38 \%)$ & $10(22 \%)$ \\
\hline \multicolumn{3}{|c|}{ Place of Residence ${ }^{a}$ (Province) } \\
\hline Havana & $50(79 \%)$ & $33(77 \%)$ \\
\hline Artemisa & $12(19 \%)$ & 0 \\
\hline Villa Clara & 0 & $5(12 \%)$ \\
\hline Other & $1(2 \%)$ & $5(12 \%)$ \\
\hline \multirow[t]{5}{*}{ Putative way of infection ${ }^{a}$} & Multiple blood transfusions 10 (16\%) & Sexually-transmitted \\
\hline & Hemodialysis therapy 21 (33\%) & Heterosexual 13 (30\%) \\
\hline & Liver transplantation 7 (11\%) & MSM $26(60 \%)$ \\
\hline & Health-care workers $4(6 \%)$ & MSM and exposure to tattooing $4(9 \%)$ \\
\hline & Frequent parenteral medication $1(2 \%)$ & \\
\hline HIV-1 infection stages & No demonstrable or unknown 20 (32\%) & \\
\hline AIDS patients & & $37(86 \%)$ \\
\hline Non-AIDS patients & & $6(14 \%)$ \\
\hline
\end{tabular}

MSM: Men who have sex with men.

a Data available for $43 \mathrm{HCV} / \mathrm{HIV}$ co-infected patients.

Analyser (Applied Biosystems, Foster City, CA, USA). Sequence assembly was done using DNASTAR (DNASTAR, Inc, Madison, WI, USA). The new sequences were compared with a set of references and with sequences obtained by BLAST (HCV-1a (EU781753 and EU255993), HCV-1b (JN120912, EU482849, HM638188, AB523065, FJ390397, EU155370, EF407459, EU155376, AF356827, EU081424 and AB523141), HCV-1C (AY051292 and D14853), HCV-2a (AB047640) and HCV-2b ( $\underline{\text { D10988 }})$.

The sequences were aligned using the CLUSTAL W program (www.clustal.org). ${ }^{19}$ Phylogenetic and molecular evolutionary analyses were conducted using MEGA version 4 (www.megasoftware.net) ${ }^{20}$ and a phylogenetic tree was created by the neighbour-joining method applied to the distance matrix obtained under the Kimura two-parameter model. As a measure of the robustness of each node, we utilized the bootstrap method (1000 pseudo-replicas).

Seventeen Cuban HCV sequences characterized in the present study and selected based on their unique characteristics have been submitted to EMBL Nucleotide Sequence Database under the indicated accession numbers: isolate CUBA1 (FR872799), CUBA7 (FR872800), CUBA13 (FR872801), CUBA10 (FR872802), CUBA16 (FR872803), CUBA19 (FR872804), CUBA24 (FR872805), CUBA25 (FR872806), CUBA26 (FR872807), CUBA36 (FR872808), CUBA37 (FR872809), CUBA39 (FR872810), CUBA42 (FR872811), CUBA43 (FR872812), CUBA45 (FR872813), CUBA47 (FR872814) and CUBA51 (FR872815).

\subsection{Statistical analysis}

Statistical analysis was carried out using the $\chi^{2}$ test and Fisher's exact test.

\section{Results}

3.1. Distribution of HCV genotypes according to laboratory assay and study population

Of the 109 anti-HCV positive samples, 84 (77\%) tested positive for HCV-RNA (48 and 36 samples of HCV-monoinfected and HCV/HIV co-infected patients respectively). Of these, samples belonging to the first subgroup were genotyped by RFLP, with genotype-specific primers and confirmed by sequence analysis: 8 (17\%) belonged to genotype $1 \mathrm{a}$ and $39(81 \%)$ to genotype $1 \mathrm{~b}$. All techniques yielded similar results, except for one sample in which a mixed genotype $1 b / 3 a$ was obtained with genotype-specific primers, while RFLP and sequencing only detected genotype $1 \mathrm{~b}$.

For the 36 samples belonging to HCV/HIV co-infected patients an analysis based on genotype-specific primers only was done: three samples (56\%) belonged to genotype $1 \mathrm{a}, 30(83 \%)$ to genotype $1 \mathrm{~b}, 2(6 \%)$ to a mixed infection with genotypes $1 \mathrm{a} / 3 \mathrm{a}$, one $(3 \%)$ to a mixed infection with genotypes $1 \mathrm{~b} / 4 \mathrm{a}$ and one (3\%) to a triple infection with genotypes $1 \mathrm{a} / 1 \mathrm{~b} / 3 \mathrm{a}$.

Overall, all 84 HCV-RNA positive samples were genotyped using one or more techniques. Of these, 79 (94\%) were infected with a single virus genotype. Genotype $1 \mathrm{~b}$ was the most frequent $(69 / 84,82 \%, p=0.04)$ followed by genotype 1a (10/84, 12\%). Mixed genotypes were found in five samples, with genotype $1 \mathrm{~b}$ present in three $(60 \%$; Table 2).

In the analysis of the HCV genotype distribution according to the subgroups HCV-monoinfected $(n=48)$ and HIV/HCV co-infected patients $(n=36)$, a predominance of genotype $1 \mathrm{~b}$ was observed in both subgroups, 
Table 2

HCV genotype distribution in monoinfected and HIV co-infected patients, Cuba

\begin{tabular}{|c|c|c|c|c|c|c|c|}
\hline \multirow[t]{3}{*}{ Groups } & \multirow[t]{3}{*}{ RNA positive (\%) } & \multicolumn{6}{|c|}{ Genotype (\%) } \\
\hline & & \multirow[t]{2}{*}{$1 \mathrm{a}$} & \multirow[t]{2}{*}{$1 \mathrm{~b}$} & \multicolumn{4}{|l|}{ Mixed } \\
\hline & & & & $1 a / 3 a$ & $1 b / 3 a$ & $1 b / 4 a$ & $1 a / 1 b / 3 a$ \\
\hline HCV-monoinfected patients, $n=63$ & $48(76)$ & $8(17)$ & $39(81)$ & 0 & $1(2)$ & 0 & 0 \\
\hline HCV/HIV co-infected patients, $n=46$ & $36(78)$ & $2(6)$ & $30(83)$ & $2(6)$ & 0 & $1(3)$ & $1(3)$ \\
\hline Total, $n=109$ & $84(77.1)$ & $10(11.9)$ & $69(82.1)$ & $2(2.4)$ & $1(1.2)$ & $1(1.2)$ & $1(1.2)$ \\
\hline
\end{tabular}

corresponding to $39(81 \%)$ and $30(83 \%)$ patients respectively, while genotype 1 a was present in $8(17 \%)$ and $2(6 \%)$ samples respectively (Table 2 ).

$\mathrm{HCV} / \mathrm{HIV}$ co-infected patients had a higher frequency of mixed infections $(4,11 \%)$ than HCV-monoinfected patients $(1,2 \% ; \mathrm{p}=0.08)$. Genotype $3 \mathrm{a}$ was more frequent in the HCV/HIV co-infected patients than in the HCVmonoinfected patients, corresponding to $3(8 \%)$ and $1(2 \%)$ of the samples respectively $(\mathrm{p}=0.18)$. Genotype $4 \mathrm{a}$ was found only in the HCV/HIV co-infected subgroup.

There was no association between genotype and demographic variables when analysis was performed for HCV genotype distribution in general and for mixed infections in particular. In HCV/HIV co-infected patients mixed infections of HCV (two or more genotypes) showed a tendency to be more frequent $(\mathrm{p}=0.11$ ) in patients older than 45 years of age and a higher frequency of genotype $1 \mathrm{~b}$ in those with white $\operatorname{skin}(\mathrm{p}=0.06)$.

According to the place of residence of the enrolled patients, mixed infections were found in patients from Havana $(n=4)$ and from Artemisa $(n=1)$, a province located very close to Havana. Analyzing HCV genotype distribution according to sexual orientation and putative way of HIV infection in the HCV/HIV co-infected patients showed that subtype 1a was found only in men who have sex with men (MSM) whereas subtype 1b was found in MSM (16/30, $53 \%)$, in the heterosexual group (10/30,33\%) and in MSM with exposure to tattooing $(1 / 30,3 \%)$. Interestingly, mixed infections were present only in MSM (one of them with exposure to tattooing) and all of them were patients with AIDS.

\subsection{Phylogenetic analysis}

Figure 1 shows the phylogenetic relatedness based on $286 \mathrm{nt}$ of the $5^{\prime} \mathrm{NCR}$ and part of the core of 17 unique strains derived from HCV-monoinfected patients. HCV isolates from Cuba clustered in genotype 1 with high bootstrap values. Two isolates clustered with sequences of subtype $1 \mathrm{a}$ and 15 clustered with sequences of subtype $1 \mathrm{~b}$. All the viruses were isolated from patients living in Havana $(n=12)$, Artemisa $(n=4)$ and other province $(n=1)$.

Cuban strains of subtype $1 \mathrm{a}$ (13 and 16) isolated from patients living in Havana and of subtype $1 \mathrm{~b}$ (39 and 47) isolated from patients living in Artemisa, clustered together and distinct from the other strains from Cuba. Additionally, these strains were isolated from patients with common putative way of $\mathrm{HCV}$ infection.

The maximal genetic distance calculated for the sequences from Cuba was $2.51 \%$ among the genotype $1 \mathrm{~b}$ strains and $0.35 \%$ among the $1 \mathrm{a}$ strains. The strains from
Cuba were similar or even identical to viruses from Asia, Europe and North America collected around the same time (Figure 1).

\section{Discussion}

In the present study we characterized the HCV genotype distribution in Cuba and performed a phylogenetic analysis of the strains based on $286 \mathrm{nt}$ of the $5^{\prime}$ NCR and part of the core of the HCV genome recovered from monoinfected patients. Previous reports of HCV genotyping in Cuba point to genotype $1 \mathrm{~b}$ as the most prevalent. Roca et al. ${ }^{13}$ used a PCR-based genotyping method and reported the presence of $1 \mathrm{~b}$ in $93.3 \%$ of cases of single, dual or multiple infections. Other genotypes included $1 \mathrm{a}, 2 \mathrm{~b}$ and $3 \mathrm{a}$, but always in combination with 1b. Padron et al. ${ }^{14}$ found that $92.9 \%$ of the patients included in their study had genotype $1 \mathrm{~b}$. In this study HCV genotyping was performed using a nested PCR procedure with specific primers for each described genotype. They also reported a high rate of multiple genotypes. A recent study using sequencing and phylogenetic analysis derived from the HCV core region also revealed the presence of genotype 1 in all samples tested, with a predominance of subtype $1 \mathrm{~b} .{ }^{15}$ None of the previous studies reported genotype 4 in the Cuban population. It seems that in Cuba the most prevalent genotype is $1 \mathrm{~b}$, followed by $1 \mathrm{a}$, with a minor circulation of $2 \mathrm{~b}, 3 \mathrm{a}$ and $4 \mathrm{a}$. Genotypes $1 \mathrm{a}, 1 \mathrm{~b}$ and $3 \mathrm{a}$, have become very widely distributed as a result of transmission through blood transfusion over the past 30-70 years and now represent the vast majority of infections in Western countries. ${ }^{21}$ These are the genotypes that are encountered most commonly in the clinical setting and for which much information on treatments has been collected.

This study found five samples (6\%) with mixed genotype infection; but always in combination with genotype 1 , similar to previous reports from Cuba. ${ }^{13,14}$ The gold standard methodology for genotyping $\mathrm{HCV}$ in serum samples is sequencing. However, in many diagnostic virology laboratories with no sequencing facilities, other methods are required, with RFLP being the most preferable methodology. ${ }^{22}$ In our experience, PCR and genotyping using specific primers ${ }^{11}$ is faster, less expensive than other genotyping methods and primers used for the PCR showed high homology when compared with consensus sequences of the respective genotype.

$\mathrm{HCV}$ co-infection has emerged as a significant factor influencing the survival of HIV patients. Patients with HCV/HIV co-infection have a faster rate of fibrosis progression resulting in more frequent occurrences of cirrhosis, 


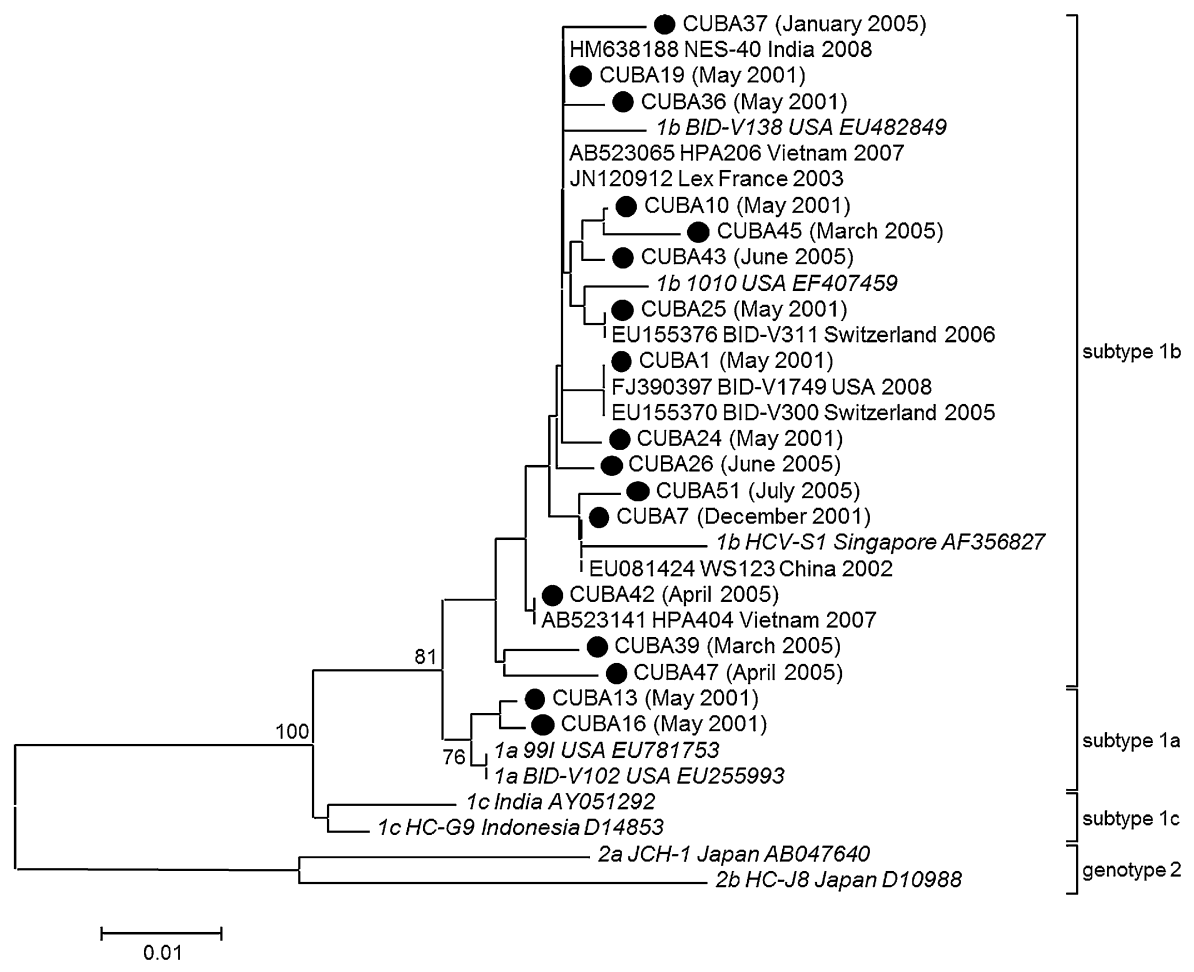

Figure 1. Phylogenetic analysis of 17 unique HCV strains from Cuba (marked with a black dot) compared to references sequences of genotypes 1 and 2 and sequences obtained by BLAST search. The Cuban strains in the tree are shown by their names and the collection time is indicated behind in parentheses. Each reference strain is identified by genotype and subgenotype, strain name, location and GenBank accession number (Italics). The sequences obtained by BLAST search are labeled with their GenBank accession number, strain name, location and year of collection. The tree was constructed using the neighborjoining method and the Kimura 2-parameter model and is based on $286 \mathrm{nt}$ of the $5^{\prime}$ NCR and part of the core of HCV Numbers at the nodes show bootstrap percentages over 1000 replicates (only values $\geq 70$ are shown). The bar indicates genetic distance.

end-stage liver disease, and hepatocellular carcinoma. ${ }^{9}$ In this scenario, particularly HCV genotype 4 has become increasingly prevalent in European countries and Australia in the last years. ${ }^{23-26} \mathrm{HCV}$ genotype 4 may spread quickly among the general population once it is introduced in a given region. ${ }^{25}$ In the Americas genotypes 1 to 4 have been reported in $\mathrm{HCV} / \mathrm{HIV}$ co-infected patients, with genotype 1 as the most frequently found followed by genotype 3 and mixed infections. ${ }^{27-29}$ Epidemiological data demonstrate the recent introduction of $\mathrm{HCV} 4 \mathrm{a}$ and $4 \mathrm{~d}$ subtypes into the Caribbean. In 2004, Martial et al. ${ }^{27}$ reported genotype 4 in this region (2.8\% and 5.9\% samples from HCV-monoinfected and HCV/HIV co-infected patients from Martinique Island, respectively).

This is the first report of HCV genotype 4a in Cuba, specifically in an HIV positive patient. In the clinical setting, the emergence of HCV genotype 4 in the Caribbean and its presence in Latin America should be considered because it is difficult to treat and has a sustained virological response rate of only about $60 \%{ }^{30}$

HCV transmission is mainly via parenteral routes, with differences in developed and developing countries. In the developing world, unsafe therapeutic injections and transfusions are likely to be the major modes of transmission. ${ }^{6}$ Patients with known risk factors such as multiple transfusions, multiple percutaneus procedures, immunosuppression and frequent contact with blood and blood products place these individuals at risk to $\mathrm{HCV}$ infection.

In HIV-positive cohorts with a single predominant risk factor for acquiring HIV, the proportion of patients coinfected with HCV depends largely on the primary HIV risk factor. ${ }^{6}$ In addition, it is well known that: HCV sexual transmission is enhanced by high-risk sexual behaviour such as multiple casual partners and anal intercourse, the use of recreational drugs and HIV co-infection; the HCV-RNA has been found with higher levels in semen of HCV/HIV co-infected patients than in HCV-monoinfected patients; and the incidence of HCV infection is increasing in HIVinfected MSM and phylogenetic analysis has revealed a large international network of HCV transmission among this population. ${ }^{26,31,32}$

Routes of transmission of HIV infection in Cuba are different in some aspects from that in other countries as the transmission by intravenous drug use and infection by blood and blood derivatives is extremely rare. Instead, 99\% of the cases contracted the infection through sexual relations, $77 \%$ of the HIV positive adults are men, most (85\%) of the detected HIV positive men were reported as MSM, and most of the HIV positive women reported having had sex with MSM. ${ }^{33,34}$ Taking into account the results of the present study and the epidemiological characteristics of the HIV epidemic in Cuba, the possibility of the spread of genotype $4 \mathrm{a}$ in this population or in the general population 
must be an alert to the health authorities and clinicians have to be aware of this circumstance.

Mixed HCV infection was found in a patient with history of frequent parenteral medication for severe chronic disease and in four samples from MSM. This mixed infection is possibly due to multiple exposures around the time of primary infection, taking into account that ongoing or chronic HCV infection does not protect from reinfection, at least experimentally. ${ }^{35}$ Another possibility is simultaneous infection with several genotypes. The presence of genotype 1 in all of these samples, reinforces the data reported here and previously in Cuba of the high prevalence of genotype 1. Of interest is the presence of genotype 3 in four samples, three of them (75\%) being HCV/HIV co-infected persons. Similar results have been reported in Brazil and in Martinica. ${ }^{27,36}$

The lack of association between a specific HCV genotype and demographic characteristics was not unexpected due to the predominance of genotype $1 \mathrm{~b}$ in $82 \%$ of the global population and also in both subgroups included in this study. The tendency of HCV/HIV patients older than 45 years of age to have mixed infections could be due to the life style of this group with high-risk sexual practices associated with HCV transmission. Mendes-Correa and co-workers reported that age older than 30 years was strongly associated with hepatitis $\mathrm{C}$ transmission in HIV-infected patients in Brazil, ${ }^{36}$ but they did not report detection of $\mathrm{HCV}$ mixed infections in a series where most patients reported more than two risk factors for HCV transmission, ${ }^{29}$ which is possibly related to the genotyping method or the risk factors associated with HIV infection in Brazil. Similar to our findings, Marcial et al. reported the association between HCV subtype 1b and old age in the HCV/HIV-coinfected group. ${ }^{27}$

Studies in the Caribbean Islands ${ }^{27}$ and in the Continental region of the Americas ${ }^{37,38}$ report the existence of the six genotypes of HCV with the predominance of genotype 1 (subtypes a and b) with some countries having a geographic distribution pattern of different HCV genotypes. The molecular epidemiology and natural history of HCV shows a wide range of genotypes circulating among the main risk groups for HCV infection and in populations with no apparent risk for HCV infection around the world. In Cuba, prevalence of HCV genotypes in the two population groups studied is consistent with the HCV genotype distribution reported for the Latin America region, ${ }^{39}$ although further investigations will be performed to confirm the detection and spread of genotype 4a in $\mathrm{HCV} / \mathrm{HIV}$ co-infected patients and in the general population.

Cuban HCV sequences were identical, or very similar to, strains from Asia, Europe and North America (Figure 1). These findings were not entirely unexpected, because of the long history of communication between these regions and Cuba. Information regarding HCV phylogenetic analysis is limited in Cuba, but recently Gonzalez-Horta and collaborators ${ }^{15}$ studying an HCV core fragment reported that Cuban HCV sequences showed highest similarity with isolates from the US and Europe, very similar to our findings. Blood transfusions and medical invasive procedures were the main potential modes of HCV infection in the population analyzed by Gonzalez-Horta, also similar to the HCV-monoinfected population shown in the present study.

The analysis showed that some Cuban strains cluster together and are distinct from the other strains from Cuba. This is important to consider because these strains were isolated from patients with a common place of residence, year of collection and putative route of infection. More studies with different HCV genome regions are needed in order to add data regarding the genetic diversity of HCV in Cuba. Also, further studies may provide important evidence for understanding the origin and spread of HCV infection in the Caribbean region, a place with a mixed population from Europe, Africa and Asia, but also geographically close to the American continent.

In conclusion, this report presents the prevalence of $\mathrm{HCV}$ genotypes in monoinfected and HIV co-infected patients and for the first time the detection of subtype $4 \mathrm{a}$ in a patient co-infected with HIV in Cuba. Additionally HIV-infected MSM with high-risk sexual practices should be aware of sexually transmitted HCV superinfection and reinforce the necessity of take appropriate preventive measures.

Authors' contributions: LARL and MGR conceived the study; LARL, MCMV, MBC, SSF, JMH, SDC and HPS designed the study; LARL, JMH, HPS and JH analyzed and interpreted the data; LARL, MBC, SSF, MSW, MS, MBN and LVA collected and processed the samples and interpreted the results; LARL, HPS, JMH and MGR drafted the paper; MCMV, MBC, SSF, JMH, SDC, and JH revised the paper. All authors contributed to and read and approved the final manuscript. LARL and MGR are guarantors of the paper.

Acknowledgments: The authors are grateful to Mrs. Theomira Mauadie Azevedo do Carmo, Itatiana Rodart and Gisele Lopes Barreto from the LPBM/CPqGM), FIOCRUZ Bahia-Brazil, for the technical assistance including the standardization of the PCR-genotyping method.

Funding: None.

Competing interests: None declared.

Ethical approval: This investigation was approved by the Institutional Review Board Ethics Committee of the Institute of Tropical Medicine Pedro Kourí, Havana, Cuba and maintained patient anonymity.

\section{References}

1. Wasmuth JC. Hepatitis C - Epidemiology, transmission and natural history. In: Mauss S, Berg T, Rockstroh J, Sarrazin C, Wedemeyer H, editors. Hepatology. Duesseldorf: Flying Publisher; 2009. p. 37-46.

2. Martínez JF, Pérez A, Montalvo C, Rodríguez L, Gutiérrez A, Rodríguez K. Serological prevalence and risk factors associated to hepatitis $C$ in the municipalities of Playa and Marianao [in Spanish]. Rev Panamericana Infectol 2005; 7:8-14

3. Padron G, Arus E, Rivera L, Viña A, Bacallao J. The hepatitis C virus infection in Cuba. Prevalence, antibodies and risk factors. Biotecnología Aplicada 1995;12:94-5.

4. Ballester J, Rivero R, Villaescusa R, et al. Hepatitis $C$ virus antibodies and other markers of blood-transfusion-transmitted infection in multi-transfused Cuban patients. J Clin Virol 2005;34 (Suppl 2):S39-46.

5. Bello M, Montalvo MC, Rodríguez L, et al. Hepatitis C virus in HIV-positive patients (in Spanish). Rev Cubana Med Trop 
2008;60, http://scielo.sld.cu/scielo.php?script=sci_arttext\&pid=S0375$07602008000300012 \& \operatorname{lng}=$ es\&nrm=iso\&tlng=es [accessed 2 May 2010].

6. Shepard CW, Finelli L, Alter MJ. Global epidemiology of hepatitis C virus infection. Lancet Infect Dis 2005;5:558-67.

7. Hadziyannis SJ, Koskinas JS. Differences in epidemiology, liver disease and treatment response among HCV genotypes. Hepatol Res 2004;29:129-35.

8. Pang PS, Planet PJ, Glenn JS., The evolution of the major hepatitis C genotypes correlates with clinical response to interferon therapy. PLoS One 2009;11;4:e6579.

9. Singal AK, Anand BS. Management of hepatitis $C$ virus infection in HIV/HCV co-infected patients: clinical review. World J Gastroenterol 2009;14:15, 3713-24.

10. Laperche S, Lunel F, Izopet J, et al. Comparison of hepatitis C virus NS5b and 5'noncoding gene sequencing methods in a multicenter study. $J$ Clin Microbiol 2005;43:733-9.

11. Lerat $\mathrm{H}$, Rumin S, Habersetzer F, et al. In vivo tropism of hepatitis $C$ virus genomic sequences in hematopoietic cells: influence of viral load, viral genotype and cell phenotype. Blood 1998;91:3841-9.

12. Khaliq S, Vahan S, Pervaiz A. Sequence variability of HCV Core region: Important predictors of $\mathrm{HCV}$ induced pathogenesis and viral production. Infect Genet Evol 2011;11:543-56.

13. Roca J, Ahmad M, Panda SK, Padrón G, Jameel S. Hepatitis C virus genotyping in developing countries: results from Cuba, India and Turkey. Biotecnol Apl 1999;16:88-92.

14. Padron G, Roca J, Jameel S, Arus E, Rivera L. The hepatitis C virus infection in Cuba: antibody pattern and genotypes. Biotecnol Apl 1995;12:93-4.

15. González-Horta EE, Marante J, Amador-Cañizares Y, et al. Analysis of hepatitis $C$ virus core encoding sequences in chronically infected patients reveals mutability, predominance, genetic history and potential impact on therapy of Cuban genotype 1b isolates. Eur Rev Med Pharmacol Sci 2011;15:1320-7.

16. Chan SW, McOmish F, Holmes EC, et al. Analysis of a new hepatitis C virus type and its phylogenetic relationship to existing variants.J Gen Virol 1992;73:1131-41.

17. Davidson F, Simmonds P, Ferguson JC, et al. Survey of major genotypes and subtypes of hepatitis $C$ virus using RFLP of sequences amplified from the 5'non-coding region. J Gen Virol 1995;76:1197-204.

18. Buck J, Purcell RH, Miller RH. Importance of primer selection for the detection of hepatitis $C$ virus RNA with the polymerase chain reaction assay. Proc Natl Acad Sci 1992;89:187-91.

19. Thompson JD, Higgins DG, Gibson TJ. CLUSTAL W: improving the sensitivity of progressive multiple sequence alignment through sequence weighting position-specific gap penalties and weight matrix choice. Nucleic Acid Res 1994;22:4673-80.

20. Tamura K, Dudley J, Nei M, Kumar S. MEGA4: Molecular Evolutionary Genetics Analysis (MEGA) software version 4.0. Molecular Biology and Evolution 2007;24:1596-9.
21. Simonds P. Genetic diversity and evolution of hepatitis C virus- 15 years on. J Gen Virol 2004;85:3173-88.

22. Furione M, Simoncini L, Gatti M, Baldanti F, Revello MG, Gerna G. HCV genotyping by three methods: analysis of discordant results based on sequencing. J Clin Virol 1999;13:121-30.

23. Nguyen MH, Keeffe EB, Chronic Hepatitis C. Genotypes 4 to 9. Clin Liver Dis 2005;9:411-26.

24. Matera G, Lamberti A, Quirino A, et al. Changes in the prevalence of hepatitis $C$ virus (HCV) genotype 4 in Calabria, Southern Italy. Diag Microbiol Infect Dis 2002;42:169-73.

25. Echeverria JM, León P, Pozo F, Avellón A. Follow-up of the prevalence of hepatitis $C$ virus genotypes in Spain during a nine-years period (1996-2004). Enferm Infecc Microbiol Clin 2006;24:20-5.

26. Van de Laar T, Pybus O, Bruisten S, et al. Evidence of a large, international network of HCV transmission in HIV-positive men who have sex with men. Gastroenterol 2009;136:1609-17.

27. Martial J, Morice J, Abel S, et al. Hepatitis C Virus (HCV) Genotypes in the Caribbean Island of Martinique: Evidence for a Large Radiation of HCV-2 and for a Recent Introduction from Europe of HCV-4.J Clin Microbiol 2004;42:784-91.

28. Quarleri JF, Bolcic FM, Bouzas MB, et al. HCV genotype distribution among HIV co-infected individuals in Argentina: relationship with host and viral factors. Acta Gastroenterol Latinoam 2007;37:76-83.

29. Mendes-Correa MC, Cavalheiro NP, Mello C, Barone AA, Gianini RJ Genotypic distribution of hepatitis $C$ among hepatitis $C$ and HIV coinfected patients in Brazil. Int J STD AIDS 2008;19:595-9.

30. Brown RS. Recent Advances in Hepatitis C: Highlights from the 2010 AASLD Meeting. Gastroenterol Hepatol 2011;7:4-16.

31. Ghosn J, Thibault V, Delaugerre C, et al. Sexually transmitted hepatitis C virus superinfection in HIV/hepatitis C virus co-infected men who have sex with men. AIDS 2008;22:658-61.

32. Danta M, Dusheiko GM. Acute HCV in HIV-positive individuals- a review. Curr Pharm Des 2008;14:1690-7.

33. de Arazoza H, Joanes J, Lounes R, et al. The HIV/AIDS epidemic in Cuba: description and tentative explanation of its low HIV prevalence. $B M C$ Infect Dis 2007;9;7:130.

34. Gorry C. Cuba's national HIV/AIDS program. MEDICC Rev 2011;13:5-8.

35. Farci P, Alter HJ, Govindarajan S, et al. Lack of protective immunity against reinfection with hepatitis C virus. Science 1992;258:135-40.

36. Mendes-Correa MC, Barone AA, Gianini RJ. Risk factors associated with hepatitis $C$ among patients co-infected with human immunodeficiency virus: a case-control study. Am JTrop Med Hyg 2005;72:762-7.

37. Nainan OV, Alter MJ, Kruszon-Moran D, et al. Hepatitis C virus genotypes and viral concentrations in participants of a general population survey in the United States. Gastroenterol 2006:131:478-84.

38. Rivas-Estilla AM, Cordero-Pérez P, Trujillo-Murillo Kdel C, et al. Genotyping of hepatitis $\mathrm{C}$ virus (HCV) in infected patients from Northeast Mexico. Ann Hepatol 2008;7:144-7.

39. Cristina J. Genetic diversity and evolution of hepatitis $C$ virus in the Latin American region. J Clin Virol 2005;34(Suppl 2):S1-7. 